drive the fan is only nine hundredths of a horsepower, and its capacity is a third of a cubic metre per second. The electrical vehicle used for transporting the degasser is operated by an 80 -volt battery. According to recent experiments, an area contained by a circumference of about 300 metres and covering sewers approximately 1,000 metres in total length can be degassed in 10-15 minutes. It was proved that the ordinary method of circulating fresh air in the system was useless and sometimes dangerous.

\section{Effects produced by Ultra-Sonic Vibrations}

As abstract of a paper read by Dr. L. A. Chambers of the School of Medicine of the University of Pennsylvania to the Institute of Radio Engineers, on the effects produced by intense sounds on liquids, has been issued by Science Service, of Washington, D.C. The intense sounds produce impacts on the liquids comparable to mechanical blows and make changes in them which will sometimes be useful in science and industry and should prove most useful in the field of medicine. Dr. Chambers uses sound vibrations having a frequency of 1,200 cycles per second and an intensity which is at least equal to one hundred times that of a large orchestra when playing together. These vibrations are produced by electric oscillators and kindred devices. When milk has been subjected to these vibrations, it acts as if it were purely homogeneous. The cream cannot be made to separate from it, and it is stated that it is now more digestible. Rapid progress is being made in the field of medical research, and it has been shown that certain organisms are killed by the pressure pulses. Dr. Chambers' researches have shown that these intense mechanical vibrations will be most useful for the preparation of serums. Whisky subjected to this treatment aged very rapidly. Samples subjected to it for seven hours produced a whisky which experts stated to be equivalent to one which had been aged in the wood for four years in the usual way.

\section{Forests in the Canadian Prairie Provinces}

A Forest Service Bulletin, No. 88, has been issued under the auspices of the Department of the Interior, Canada (Ottawa, Printer to H.M. the King, 1936) entitled "Forest and Forest Industries of the Prairie Provinces" by J. D. B. Harrison of the Division of Forest Economics. The Prairie Provinces occupy a part of the interior continental plain of North America and have thus many characteristics which differentiate them from other parts of the Dominion. A National Forest Inventory was commenced jointly in 1929 by the Dominion and provincial forest authorities but had to be retarded owing to the general economic situation; in spite of this it has proved possible to collect a large amount of information on the subject of these Prairie Provinces and this the author summarizes in the present bulletin. A brief but comprehensive review of the principal factors affecting the forests, together with a description of the forests themselves, is given. The dominance of agriculture as the principal industry of the region is emphasized, and questions of population and of communications dealt with, in order to place the forest resources in their proper economic perspective. Sufficient historical material is included, in the appropriate chapters, to explain the course of events leading up to the present situa. tion. The bulletin is written by an economic research officer from the purely economic point of view. It is, however, none the less disquieting to observe that the forests of a country are still mainly regarded from the point of view of what they can be made to yield in produce to man, whilst the protection they offer to mankind as a whole, and to certain of the natural resources of the country, are so little appreciated until almost irretrievable damage by over-exploitation has been done.

\section{Agricultural Statistics}

The International Institute of Agriculture, Rome, has now published the sixth of its economic commentaries, "The World Agricultural Situation in 1934-5" (price 25 lire). As in the preceding issue, the volume is divided into two parts, the first of which deals with world agriculture and the second with the individual policy and conditions in the different countries. Both sections contain a wealth of interesting material of which it is impossible to give more than the briefest outline. Under the first heading, an analysis is made of the more important changes and trends in world economy as influenced by national planning, together with a survey of the market conditions of the principal agricultural crops and livestock. The year under review was a period of adjustments and adaptations involved in the carrying out of schemes of planning and control rather than a period of new initiations in economic organization, the outstanding feature being the increasing development of economic autarchy, which in theory stands almost universally condemned. The effects of this tendeney, economic, political and technical, are discussed at length, and it is shown that greater stability is now being sought by the formation of large economic combinations between countries usually with close political associations. Further, the various forms of industrialization that are taking place in the so-called agricultural countries are shown to be producing far-reaching repercussions upon international economic relations. The information in the second part is principally concerned with Government measures for farm relief and the economic conditions of agriculture prevailing in the various countries. More than thirty countries are considered, information with regard to Austria, Portugal and Portuguese Colonies being included in this issue for the first time. Data for Argentina and Poland which were omitted in the last issue of the commentary are again included.

\section{Medical Centre for Moscow}

A LARGE medical centre which will include the All-Union Institute of Experimental Medicine, the institutes of the State Health Department, the Second Moscow Medical University and a traumatological institute, will be built on the outskirts of Moscow 